\title{
As mulheres da Ilha das Caieiras: relacionamento interpessoal e cooperação na formação e no funcionamento de uma cooperativa
}

\author{
Raquel Ferreira Miranda ${ }^{\mathrm{I}}$ e Agnaldo Garcia ${ }^{\mathrm{II}}$ \\ ${ }^{\mathrm{I}}$ Universidade Federal de Viçosa (Campus Rio Paranaíba) \\ ${ }^{\text {II }}$ Universidade Federal do Espírito Santo (Departamento de Psicologia Social e do Desenvolvimento)
}

\begin{abstract}
Este trabalho analisa alguns aspectos dos relacionamentos interpessoais entre as participantes de uma cooperativa de produção da Ilha das Caieiras, na cidade de Vitória, Espírito Santo, buscando compreender o desenvolvimento histórico e a situação atual desses relacionamentos. Participaram da pesquisa 12 mulheres cooperadas. Os dados foram obtidos por meio de entrevistas semiestruturadas com as participantes e de observação das instalações e da rotina de trabalho na cooperativa. Foram analisados por análise de conteúdo e organizados de acordo com o referencial teórico de Robert Hinde. São destacados três pontos em relação ao histórico e à situação contemporânea dos relacionamentos: uma história de sobreposição de diferentes formas de relacionamentos: familiar, comunitário e de trabalho; a transposição de padrões de relacionamento familiares e comunitários para as relações de trabalho; a necessidade de um amplo planejamento de treinamento para o desenvolvimento interpessoal e organizacional.
\end{abstract}

Palavras-chave: Relacionamento interpessoal, Cooperação, Cooperativismo.

The women from Ilha das Caieiras: interpersonal relationship and cooperation regarding setup and maintenance of a cooperative

Describing and analyzing the interpersonal relationship aspects is the aim of the present study, focusing the cooperation process among the actors of a cooperative based on Ilha das Caieiras in the city of Vitoria, in the state of Espírito Santo in Brazil. 12 women of the cooperative took part in this pool. The research data were collected during partially-structured interviews, during facilities visitation, work routine observation. The data were analyzed using content analysis and they were organized according to theoretical reference by Robert Hinde. Three major points are remarked regarding the history and the contemporary situation of the relationships: a history of overplacing different forms of relationships, family, community and at work; transposing relationship patterns from the family and community to the work relations; the need for a wide training plan to the interpersonal and organizational development.

Keywords: Interpersonal relationships, Cooperation, Cooperativism.

A pesquisa sobre relacionamento interpessoal tem sido marcada pela contribuição de autores de diferentes disciplinas e orientações teóricas. Entre os temas mais investigados estão o relacionamento romântico, o relacionamento familiar e as relações de amizade. Três aspectos se destacam como representativos do conteúdo dos estudos de relacionamento interpessoal: os participantes, as dimensões do relacionamento e o contexto (Garcia, 2005).

Robert Hinde é um dos autores contemporâneos que mais contribuiu para a tentativa de organização de uma "ciência do relacionamento interpessoal". De acordo com Hinde (1997), há relacionamento se os indivíduos têm uma história comum de interações passadas e o curso da interação atual é influenciado por elas. Segundo o autor, o relacionamento interpessoal faz parte de um sistema de relações com diferentes níveis de complexidade que afetam e são afetados uns pelos outros e ainda a estrutura sociocultural e o ambiente físico (Figura 1). Além de considerar as diferenças entre esses níveis, Hinde (1997) ressalta que é 
preciso vê-los não como entidades estanques, mas como processos que se inter-relacionam e se influenciam mutuamente.

Figura 1: Relações dialéticas entre níveis sucessivos de complexidade social (Hinde, 1997)

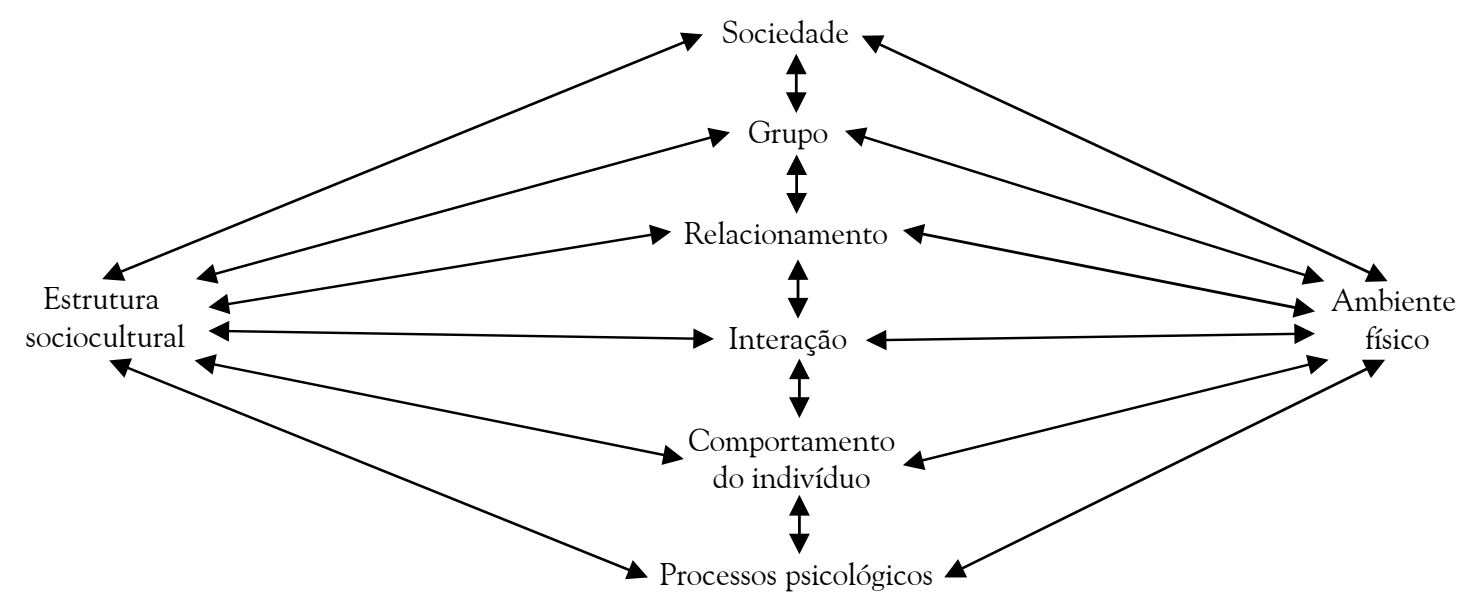

O pleno entendimento das relações exige um enfoque não somente no relacionamento, mas também no nível individual, com os participantes. $O$ curso de um relacionamento depende, em grande medida, das características psicológicas de ambos os participantes (Hinde, 2001). Portanto, a formação e as mudanças nos relacionamentos envolvem características pessoais dos participantes, como expectativas, posicionamentos quanto a normas culturais, sociais e organizacionais, autoconceito, autoestima, valores religiosos, habilidades de comunicação, dentre outras.

O tema relacionamento em ambiente organizacional representa uma proporção muito pequena dos estudos publicados em revistas internacionais especializadas sobre relacionamento interpessoal (Garcia, 2005). Um panorama mais amplo dos estudos sobre relacionamento interpessoal nas organizações surge nos periódicos internacionais de psicologia organizacional. Diferentes aspectos do relacionamento interpessoal, conforme organizados por Hinde (1997), estão presentes nessas publicações. Várias têm abordado similaridade, diferença, reciprocidade e complementaridade. Entre elas, estão pesquisas sobre diferenças de idade e seus efeitos na relação supervisor-subordinado (Finkelstein, Allen \& Rhoton, 2003; Perry, Kulik \& Zhou, 1999), sobre similaridade e complementaridade entre colegas (Tett \& Murphy, 2002), sobre os efeitos da similaridade na percepção e na avaliação (Strauss, Barrick \& Connerley, 2001), sobre os efeitos da similaridade com colegas e clientes no desempenho (Leonard, Levine \& Joshi, 2004), sobre o papel da dissimilaridade entre supervisor e subordinado (Duffy \& Ferrier, 2003) e sua influência no local de trabalho.

Outros temas também são discutidos, como o conflito e sua resolução (Pelled, Xin \& Weiss, 2001; Smith, Hamington \& Neck, 2000; Yang \& Mossholder, 2004) e relações de poder (Garcia, 2002; Morand, 2000). A percepção interpessoal tem sido investigada ao lado de outros fatores, como a comunicação (Thorsteinson \& Balzer, 1999), a influência de relacionamento afetivo para a percepção e a avaliação do outro (Lefkowitz, 2000). Ainda abordam as discrepâncias nas percepções no ambiente de trabalho (Becker, Ayman \& Korabik, 2002) e a avaliação de chefe, colega e subordinado, que, em última análise, reflete o produto de percepção (Furnham, 2002). Da mesma forma, os estudos sobre satisfação também envolvem outras dimensões, como inovação no trabalho (Janssen, 2003) e lealdade direcionada ao supervisor (Chen, 2001). 
Como influências devidas a características individuais e influências sociais, podem ser citadas as influências do contexto nas trocas entre líder e membro (Coglieser \& Schriesheim, 2000), os efeitos da personalidade do supervisor nas atitudes do subordinado (Smith \& Canger, 2004), efeitos do estilo cognitivo sobre a troca entre líder e membro (Allinson, Armstrong \& Hayes, 2001) e a influência de gênero no relacionamento patrão-empregado (Adebayo \& Udebge, 2004). Entre as etapas de relacionamento, as iniciais costumam receber maior ênfase, como a afiliação ou o ajustamento de novos funcionários (Cooper-Thomas \& Anderson, 2002) e as entrevistas com candidatos (Lievens \& Paepe, 2004; Silvester, Anderson-Gough, Anderson \& Mohamed, 2002).

Em função da natureza da organização a ser investigada, a cooperação e os elementos que a facilitam ou seus obstáculos emergem como um foco de atenção para as relações interpessoais nas cooperativas. Portanto, para se compreender melhor a dinâmica e a estrutura dos relacionamentos interpessoais em uma cooperativa, a dimensão da cooperação se destaca.

De acordo com Hinde e Groebel (1991), usa-se o termo cooperação para referir-se às ocasiões nas quais dois ou mais indivíduos, mutuamente, melhorem as possibilidades de outros alcançarem um objetivo, sendo mais provável que cooperadores recebam benefícios de atos cooperativos dos outros que os não cooperadores. Ressaltam ainda que a cooperação tende a acontecer primordialmente em pequenos grupos, entretanto, encontramos estudos que discutem como a cooperação pode ser mantida em grandes grupos (Buskens \& Snijders, 1997; Messick \& Liebrand, 1995).

Segundo Jehn e Shah (1997), a cooperação ajuda o desempenho de outro membro do grupo ou contribui para facilitar como os membros do grupo coordenam seus esforços. Os autores propõem que a cooperação é maior em grupos de amigos por causa das semelhanças em trocas sociais. A organização da cooperação, em seus aspectos práticos, exige de seus atores a comunicação de interesses, de objetivos e práticas, a respeito do que precisam falar, argumentar e decidir como partícipes de um projeto comum (Frantz, 2001).

Deutsch (1949, citado por Danheiser \& Graziano, 1982) destaca que normas e regras de natureza cooperativa e competitiva estabelecidas por um grupo social podem ser estruturadas dentro de um único contexto complexo, o qual organiza diferentes situações de relacionamento entre os indivíduos. Esse seria o caso, por exemplo, da cooperação intragrupo associada à competição intergrupo. A análise de Deutsch contribui, particularmente, para chamar a atenção para a importância do contexto, com suas regras e expectativas sociais.

A economia solidária, de acordo com Santos (2002), Singer (2001), Singer e Souza (2000), pode ser compreendida como uma alternativa de geração de renda e, por isso mesmo, ela estaria sendo utilizada como estrutura organizacional do trabalho em algumas políticas públicas com essa finalidade. Segundo Barfknecht, Merlo e Nardi (2006), a proposta do movimento de economia solidária visa reverter e superar a economia capitalista individualista e competitiva, na qual o capital e o mercado determinam a conduta e a vida dos trabalhadores. Segundo Singer e Souza (2000), os primeiros empreendimentos solidários são resultados do apoio de assessores sindicais a operários que se apossaram da massa falida de empresas, assumindo seu controle administrativo com o objetivo de manter os empregos e a renda dos trabalhadores.

Para Singer (2001), muitas cooperativas, provavelmente, passaram por períodos em que eram empresas solidárias e outros em que se assemelhavam mais a empresas capitalistas. De acordo com o autor, essas oscilações se devem à inserção econômica e social de cada cooperativa, que impregna os cooperadores ora de valores solidários e democráticos, ora de individualismo e culto à competição.

Coutinho, Beiras, Picinin e Lückmann (2005) afirmam que a economia solidária tem se disseminado cada vez mais como uma possibilidade de sobrevivência das camadas da população 
excluída do mercado formal de trabalho. Entretanto, mesmo o cooperativismo sendo visto como uma resposta aos problemas sócio-político-econômicos do sistema capitalista, não devemos considerá-lo como a terceira via, entre o capitalismo e o socialismo, mas uma forma de reinclusão no mercado de trabalho, funcionando como uma sociedade de pessoas e não de capital (Nascimento, 2005).

Segundo Singer (2001), a economia solidária compõe-se das empresas que efetivamente praticam os princípios do cooperativismo, principalmente, a autogestão. Ao se referir à autogestão, pode-se falar de organizações coletivas que adotam, geralmente, uma estrutura mais horizontal. As tomadas de decisões são compartilhadas pelo grupo, diferentemente do que acontece nas organizações tradicionais ou nas empresas mercantis, cuja tomada de decisões fica restrita à direção da empresa.

Singer (2002) ressalta que há pessoas que não apresentam uma inclinação espontânea para a autogestão e buscam a inserção em cooperativas ou associações para fugir da pobreza ou para sobreviver. Dessa forma, aceitam participar desse tipo de gestão sem consciência real do seu papel, nem mesmo do papel ou da função da organização. De forma geral, ainda segundo esse autor, a autogestão é entendida como um conjunto de práticas sociais, cujo processo de decisão é regido de forma democrática, possibilitando a autonomia do coletivo. É um exercício de poder compartilhado, que apresenta relações sociais mais horizontais, com participação e responsabilidade de todos os envolvidos.

Albuquerque e Macareño (1999), Singer (2002) e Lima (1996) destacam que o estímulo inicial para o nascimento da cooperativa é a possibilidade de ser uma fonte geradora de renda. A história do nascimento da cooperativa, da sua organização pode ter impacto sobre sua forma de funcionamento, principalmente se aliada à ausência de compreensão e consciência dos cooperados quanto ao seu papel e a seu poder de intervir nessa estrutura.

Rodríguez (2002) ressalta que, além do objetivo de geração de renda, as cooperativas servem ainda como um veículo de reconhecimento social de determinadas profissões que sofrem preconceitos sociais e são constantemente discriminadas - o autor denomina esse processo de reencaixe econômico, social e identitário.

Algumas das investigações empíricas em torno do cooperativismo, autogestão e economia solidária abordam as relações interpessoais de modo positivo - considerando seu aspecto potencializador no desenvolvimento dessas organizações - ou como possíveis geradoras de conflitos e entraves (Correia \& Moura, 2001; Maciel, Sena \& Sabóia, 2006; Rocha, Zoby, Gastal \& Xavier, 2003; Scopinho \& Martins, 2003).

Lima (2004) investigou dificuldades na formação de uma cultura autogestionária entre os trabalhadores de cooperativas de produção, tendo em vista que essa opção de trabalho, mais que uma alternativa voluntária, reflete um quadro de desemprego estrutural. Além disso, a falta de participação é atribuída à baixa escolaridade dos trabalhadores e ao fato de inexistir o hábito de manifestarem-se em assembleias.

Clemente, Albuquerque e Reyes (1993) mostraram, em estudo realizado na Espanha, que a criação de cooperativas por agentes externos tem influenciado o não-comprometimento dos sócios, que as veem como órgãos assistencialistas. Essas cooperativas não nascem da conscientização e da motivação dos seus sócios, mas da influência de técnicos e de autoridades externas, contribuindo para o seu fracasso. Albuquerque (1994) alerta para a grande possibilidade de insucesso das cooperativas, considerando que o fenômeno não pode ser justificado unicamente pela carência de apoio financeiro. Outras dificuldades referem-se ao surgimento da divisão entre aqueles que falam (dirigentes) e os que apenas ouvem e obedecem (associados), negando com isso o teor participativo do sistema cooperativista.

Nasciutti, Dutra, Matta e Lima (2003) apontam contradições e desafios próprios do trabalho nas cooperativas, como as dificuldades interpessoais nas relações de poder, na tomada

\section{4}


de decisões, nas práticas de subjugação que persistem nos movimentos autogestionários. Por outro lado, reconhecem os prazeres da apropriação da força de trabalho, da disposição do tempo, da possibilidade da aprendizagem, da autoestima recuperada e a descoberta do outro como possível cooperador. Um aspecto que tem sido alvo recente dos estudos organizacionais focando organizações cooperativas envolve a ideia de redes interorganizacionais visando a cooperação entre cooperativas, com base nas relações interpessoais (Batschauer \& Campos, 2005; Gonçalves, 2005; Silva, 2004).

O objetivo da presente pesquisa foi identificar, descrever e analisar o relacionamento interpessoal, com ênfase na cooperação interpessoal, como um aspecto central para a formação e o funcionamento de uma cooperativa de produção do município de Vitória, Espírito Santo.

\section{Método}

O presente trabalho é um estudo de caso qualitativo, exploratório-descritivo, das relações interpessoais em uma organização cooperativa.

\section{Histórico da cooperativa}

Segundo dados da Organização das Cooperativas Brasileiras (OCB/ES), a referida cooperativa foi fundada em fevereiro de 1999 por 49 mulheres, que trabalhavam com o desfio do siri nas calçadas da Ilha das Caieiras. As cooperadas foram qualificadas - nas áreas de higiene, de manipulação e de técnicas de congelamento de alimentos, noções de contabilidade, formação de preços e custos - por meio de recursos financeiros disponibilizados pela Prefeitura Municipal de Vitória em parceira com o Programa Nacional de Geração de Renda (Pronager).

A criação da cooperativa visava aliar geração de trabalho e renda com a preservação de atividades tradicionais da cultura capixaba, como a coleta e o desfio de siris. Entretanto, após aproximadamente um ano, houve alteração na atividade que exerciam na cooperativa em função do baixo retorno financeiro e da saída de grande parte das cooperadas. Passaram do desfio de siri para a atividade relacionada à culinária capixaba. De modo bem simples, começaram servindo pequenas porções de "moquequinha de siri" até estabelecerem o restaurante da cooperativa das desfiadeiras.

A cooperativa contava, no momento da pesquisa, em 2007, com vinte e oito mulheres cadastradas como cooperadas. Segundo a presidente, apenas treze estavam participando efetivamente das atividades. Trabalhavam em sistema de turnos, seis cooperadas e a presidente, por turno, de segunda a sábado. A cooperativa era presidida, desde o início das atividades, pela mesma presidente eleita na única votação realizada para o cargo, em 1999. A estrutura administrativa da cooperativa, no momento da pesquisa, restringia-se à presidente e à vice. Há cinco anos não realizavam assembleias para tomada de decisões ou prestação de contas.

\section{Participantes}

Participaram da pesquisa doze mulheres, com idades entre 25 e 66 anos, dentre as treze atuantes na cooperativa no momento da pesquisa. Nove delas tinham entre 25 e 45 anos. Com relação ao nível de escolaridade, somente duas cooperadas haviam completado o segundo grau. Apenas uma cooperada identificou-se como analfabeta. A maioria (oito) havia nascido na Ilha das Caieiras e outras quatro mudaram-se para o local, há mais de 15 anos, em função dos maridos serem naturais da ilha. Dentre as entrevistadas, apenas uma não possui filhos. Dez 
cooperadas estavam vinculadas à cooperativa desde o início do processo de formação do empreendimento. Todas as cooperadas residem nas proximidades da cooperativa e possuem vínculos de parentesco com membros da cooperativa.

\section{Procedimento}

Os dados foram coletados por meio de observação in loco das atividades (produtivas e administrativas) e de entrevistas semiestruturadas com as cooperadas. Foram coletados dados sociodemográficos de todas as participantes.

A observação deu-se de forma participante de acordo com um roteiro preestabelecido. Dois aspectos foram observados: o ambiente físico e as tarefas desempenhadas. Em ambos, foram destacadas as características que poderiam afetar de forma mais direta o relacionamento entre as cooperadas. A observação foi realizada pela pesquisadora durante cada visita à cooperativa, entre os meses de outubro de 2006 e maio de 2007. Inicialmente, as visitas eram realizadas semanalmente, com duração média de duas horas, havendo variações no dia da semana e no período do dia em que ocorriam visando conhecer as rotinas estabelecidas. Durante os meses de abril e maio de 2007, houve intensificação do número de visitas e nesse período foram realizadas as entrevistas. O registro das observações foi feito em um diário de campo que, de acordo com Bogdan e Biklen (1994), é o relato escrito daquilo que o investigador ouve, vê, experiencia e pensa no decurso da coleta de dados. O diário foi construído com uma base descritiva buscando a reconstrução dos diálogos, a descrição do espaço físico, relatos de acontecimentos particulares, descrição de atividades realizadas pelas cooperadas e o comportamento do observador. E uma base reflexiva que buscava apreender mais o ponto de vista do observador, suas ideias e preocupações, sendo caracterizada por uma fase do registro mais subjetiva.

Com relação ao ambiente físico, foram feitas observações em suas dimensões macro e microespaciais. As dimensões macroespaciais dizem respeito às características geográficas da região, incluindo o local onde os funcionários residem, o deslocamento para o local de trabalho e as relações entre as cooperadas fora do ambiente de trabalho. As dimensões microespaciais referem-se à área de trabalho, com ênfase no espaço disponível e nos equipamentos. Quanto às tarefas, foi observado como era feita a atividade de receber, preparar e desfiar o siri, o preparo dos pratos servidos e o atendimento no restaurante.

As entrevistas foram orientadas por três roteiros previamente elaborados, que abordavam desde aspectos da atividade de trabalho e relacionamentos anteriores ao início da cooperativa até aspectos do trabalho e da relação entre as cooperadas no momento da pesquisa. No primeiro roteiro foram abordados aspectos do cotidiano local e de trabalho anterior à cooperativa e o impacto da urbanização da ilha, incluindo formas iniciais de cooperação, fatores facilitadores e obstáculos para sua ocorrência. No segundo roteiro foram abordadas as formas de cooperação nas atividades produtivas, fatores que facilitam e dificultam a cooperação, as concepções de cooperativa e cooperação, além de episódios de violência, disputas pela direção e presença de parentes no âmbito da cooperativa. Esses dois roteiros foram aplicados a todas cooperadas, iniciando-se a entrevista com o primeiro roteiro e em seguida utilizando-se o segundo. $\mathrm{O}$ terceiro roteiro de entrevista, específico para a presidente da cooperativa, abordou o histórico da cooperativa, as atividades produtivas, instalações, atividades administrativas, entorno social e cooperação.

As entrevistas foram individuais, realizadas na própria cooperativa, gravadas após consentimento, por escrito, das entrevistadas e transcritas pela pesquisadora. Todos os participantes assinaram o termo de consentimento livre e esclarecido para participação em pesquisa. $O$ tempo de duração das entrevistas variou de 46 minutos a 2 horas e 48 minutos. 
A análise dos dados pautou-se em uma abordagem qualitativa, sendo o conteúdo analisado por dois juízes utilizando a técnica de análise de conteúdo segundo sugerida por Bardin (1977). Ao iniciar-se o trabalho de análise de conteúdo, foi realizada uma leitura flutuante do material com o objetivo de destacar os aspectos relevantes e pertinentes ao estudo. O tratamento do material consistiu em: ordenação, classificação das coocorrências das falas, sendo extraídas as relações entre os elementos das falas. Foram elaboradas as categorias específicas de cada uma das entrevistas e, a partir das coocorrências de seu conjunto, foram definidas as categorias sínteses relativas a todo o material analisado.

A organização dos dados foi feita à luz da obra de Robert Hinde. Nesse sentido, os dados foram organizados dentro de diferentes níveis de complexidade, que compõem um sistema de relações dialéticas entre interações, relacionamentos, grupos e sociedade e desses com a estrutura sócio-cultural e o ambiente físico. $\mathrm{O}$ foco deste trabalho recai sobre o nível do relacionamento, ressaltando a importância da perspectiva temporal para sua melhor compreensão. Portanto, a organização dos dados foi baseada na história dos relacionamentos e considerando vários dos níveis de complexidade propostos por Hinde.

\section{Resultados}

\section{Caracterização do contexto}

Para uma sistematização mais clara do contexto ambiental e cultural em que está localizada a cooperativa, foram propostos dois níveis: o microambiente e o macroambiente.

As cooperadas entrevistadas, ao referirem-se ao microambiente, retratam o cenário da Ilha das Caieiras desde a infância, na época, marcado pela falta de infraestrutura básica, casas pequenas, sem acabamento e dificuldade de acesso ao centro da cidade. As atividades de trabalho eram a pesca para os homens e o desfio do siri para as mulheres. O desfio era realizado na porta das casas, com intensa convivência social durante a atividade. Para as cooperadas, a razão pela qual as calçadas tornaram-se lugar importante para a atividade de desfio tem relação com o pouco espaço das residências, com a possibilidade de manterem um relacionamento com vizinhos, que em geral também eram parentes, e de cuidarem dos filhos que brincavam nas ruas. Por não saberem como conservar o siri desfiado, tinham que vendê-lo rapidamente, sendo o desfio na rua um atrativo e uma maneira de "disputarem" os compradores, em geral, donos de restaurantes.

...as pessoas desfiavam sentadas na rua, cada uma com sua vasilhinha e as venda era menos porque não era de boa qualidade... (C7).

E você hoje você passa aqui e é muito raro você ver uma pessoa desfiando siri na rua, mas essa redondeza toda aqui era gente desfiando siri na rua e era a única atração que tinha pra você vender o seu siri (C12).

O início da atividade de desfio na cooperativa possibilitou a vivência de um novo contexto de trabalho, marcado por ser um local fechado, pela saída de casa, horário de trabalho fixo, divisão das atividades de desfio, compartilhamento de equipamentos e materiais, enfim, normas a serem respeitadas. Situações novas, pois, até então, durante o desfio, existia apenas a convivência social, não havia o compartilhamento da produção gerado pela atividade na cooperativa. 
No momento da pesquisa, o espaço físico da cooperativa estava adaptado para as atividades do restaurante. Assim, as bancadas construídas para o desfio do siri eram utilizadas como espaço para o preparo dos pratos a serem servidos e para exposição das vasilhas a serem enxutas. A falta de armários dificultava a organização dos utensílios que ficavam expostos nas bancadas ou em uma estante improvisada com tábuas de madeira que funcionava como armário. Os banheiros não foram projetados para atenderem ao público externo, havia apenas dois banheiros com entrada improvisada pelos fundos da cooperativa, sendo compartilhados para uso das cooperadas e dos clientes. O local onde os clientes eram atendidos resultou da adaptação de uma área que era originalmente um estacionamento para os clientes que comprariam o siri desfiado.

As cooperadas, ao referirem-se aos aspectos do macroambiente, o local onde está situada a cooperativa estudada, a Ilha das Caieiras, foi referência constante durante as entrevistas. Relatavam histórias da ilha que faziam referência aos tempos de adolescência. $O$ discurso das cooperadas foi marcado pelo isolamento vivido na ilha, por não manterem um contato com a cidade de Vitória, como se fossem mundos diferentes. Para as cooperadas, uma importante característica da ilha refere-se aos laços de parentesco entre os moradores e a permanência dessas famílias na ilha mantendo a tradição da pesca e do trabalho com o desfio do siri.

Aqui na ilha é só familias antigas mesmo e a ilha era um lugarzinho bem humilde mesmo, as ruas sem calçamento, bequinho, não tinha essas ruas que tem hoje e as pessoas ficavam sentadas na rua com suas faquinhas desfiando siri, qualquer lugar a gente sentava, sem touca, sem nada pra desfiar (C6).

As cooperadas expressaram que a urbanização foi fundamental para a dignidade e para reconhecimento das famílias que moravam na região. A abertura de escolas e creches propiciou melhores condições de alimentação às crianças e possibilitou maior disponibilidade de tempo para as mulheres exercerem atividades de trabalho que ajudam na renda familiar. A criação de áreas de lazer, como praça e campo de futebol, foi parte do processo de melhoria das condições de vida na ilha. Após a urbanização foi estabelecida uma proximidade entre os moradores da ilha e os demais moradores da cidade, gerando, segundo as cooperadas, um sentimento de pertencer à cidade de Vitória.

\section{Relacionamentos}

São abordados três tipos de relacionamentos que retratam aspectos relevantes para a compreensão do universo pesquisado: os relacionamentos familiares, os relacionamentos na comunidade e os relacionamentos no trabalho.

Historicamente, o relacionamento familiar é a base das relações sociais da Ilha das Caieiras. Em geral, as relações familiares não se restringem ao marido e filhos. Há um envolvimento de pais, irmãos, tios e sobrinhos, o que acarreta intervenções nas decisões e atitudes que ocorrem com um número maior de membros da família.

A carência de recursos propiciava o fortalecimento dos laços familiares e a cooperação, identificada pelas cooperadas como ajuda mútua. As dificuldades também favoreceram a inserção das mulheres nas atividades de trabalho como forma de contribuírem com a renda familiar utilizando-se dos recursos naturais da ilha.

O casamento ocorria quando ainda eram muito jovens. Muitas vezes, ele era almejado pelas mulheres para saírem da tutela e da rigidez do pai, mas, em geral, livravam-se do controle paterno e passavam ao do marido. Esse quadro é comum na história de vida de cooperadas mais velhas e repete-se com as mais jovens, apesar de um importante fator diferenciador: as mais velhas têm histórias de casamentos duradouros, mesmo quando marcado pela violência do

\section{8}


companheiro, sendo raras histórias de separação. As mais jovens têm histórias marcadas por filhos de diferentes parceiros. Contudo, a marca da violência contra a mulher no ambiente doméstico permanece.

As mudanças nas relações familiares estão relacionadas aos aspectos da vida em uma sociedade urbana, a facilidade de acesso à ilha torna-se também uma facilidade de acesso dos moradores ao mundo que existe fora da ilha. Algumas cooperadas residiram fora da ilha por certo período, entretanto, relatam que o retorno ocorreu em função do apoio familiar, da ajuda dos parentes para cuidar dos filhos, da moradia na casa dos pais e pela possibilidade de conseguir alguma fonte de renda com o siri.

Sai daqui da ilha, mas depois voltei porque é mais difícil viver lá fora sozinha, longe daqui. Aqui eu posso contar com minha família pra cuidar do meu filho, pra trabalhar também fica mais fácil porque tem o siri e a cooperativa (C8).

Essas rupturas e mudanças, identificadas como subjacentes às alterações no espaço físico da ilha, ao acesso à escolarização e a uma maior troca com o contexto externo propicia mudanças nas relações familiares, comprometendo, especialmente, a continuidade das tradições culturais, pois na época atual não há interesse dos pais de que os jovens aprendam e exerçam atividades de pesca e de desfio do siri. Há a expectativa de que os filhos sigam caminhos diferentes, que lhes propiciem maiores oportunidades de rendimento financeiro.

As participantes relatam não terem tido o apoio dos familiares no início das atividades da cooperativa, pois estes não viam com bons olhos as mulheres trabalhando fora de casa. A cultura local é baseada no trabalho individual, em que cada um pode produzir o quanto precisa para sobreviver no horário e no local em que achar mais adequado. Portanto, sair de casa e permanecer fora por certo tempo para trabalhar foi uma grande alteração nas rotinas das famílias. Problemas vivenciados na esfera doméstica passaram a ser transpostos para o trabalho comprometendo o rendimento e a boa convivência com as colegas e clientes: "Mãe não gostava não, mas eu falei que tinha que procurar o que fazer porque ela queria que eu ficasse só em casa fazendo as coisas pra ela, só em casa" (C4).

As relações na comunidade são permeadas pelas relações familiares em função da própria colonização do bairro ter sido baseada em grupos familiares que residem ainda hoje no local. As cooperadas referem-se a uma convivência muito próxima entre os moradores, as casas muito simples levavam a um cotidiano voltado para a rua. Assim, as crianças brincavam, os homens pescavam e arrumavam os barcos e as mulheres faziam suas atividades de desfio também nas calçadas.

As sócias da cooperativa relatam que, a partir do trabalho na cooperativa, passaram a ter as relações na comunidade mediadas também pelo interesse financeiro, pelas disputas de poder no trabalho que extrapolam para a comunidade. As cooperadas destacaram que havia uma espécie de intercâmbio, a cooperativa interferia no cotidiano da ilha e os moradores da comunidade julgavam-se no direito de participar do cotidiano da cooperativa. O relacionamento na comunidade também estava baseado nas relações de gênero, nas diferenças entre as atividades que deveriam ser masculinas, especialmente a pesca, e as atividades femininas na comunidade.

Bem no iniciozinho tinha um grupo que queria ser mais que os outros aqui na ilha, mas a gente tinha que ficar quieta porque brigavam por causa de liderança (C4).

Uma das coisas que atrapalhou e atrapalha a cooperativa aqui na ilha foi não ter espirito cooperativista, não conseguir em grupo, mas a primeira coisa mesma foi o dinheiro porque o pessoal daqui gosta de ganhar dinheiro todo dia, pescador gosta assim ele pescou e quer o dinheiro e desfiadeira também é assim, já é da cultura daqui, difícil de mudar mesmo com a cooperativa (C11). 
As relações de trabalho podem ser caracterizadas por dois momentos distintos, sendo o primeiro referente ao trabalho das desfiadeiras de siri e o segundo referente ao trabalho na cooperativa. O primeiro momento é marcado por uma organização do trabalho individualizada, apesar de o trabalho ser realizado em ambientes sociais, nas portas das casas. Portanto, as relações de trabalho entre as desfiadeiras não existiam propriamente, pois elas tinham um convívio social durante a realização da atividade de desfio, mas era uma atividade desenvolvida de modo independente por cada desfiadeira. No segundo momento surgem, efetivamente, as relações de trabalho entre as desfiadeiras ao desenvolverem as atividades de trabalho na cooperativa.

As participantes relataram que, durante o primeiro ano de trabalho na cooperativa, o apoio e a cooperação estavam raramente presentes. Enfrentavam dificuldades com relação à divisão das atividades de trabalho, ao controle de estoque, de vendas e à divisão dos lucros. A divisão do trabalho ocorreu diferenciando cooperadas que tinham habilidade no desfio do siri e conseguiam produzir uma grande quantidade, as que faziam a "recatagem" do siri, as que embalavam e as que cuidavam da limpeza do espaço físico. Portanto, apesar de serem desfiadeiras de siri, nem todas realizavam a atividade de desfio.

No momento da pesquisa, a organização do trabalho na cooperativa baseava-se na divisão das cooperadas em duas turmas que trabalhavam em dias alternados. Essa divisão teve implicações sobre a perspectiva de que todas fazem parte de uma única equipe. Apesar dos vários relatos de divergências entre as turmas, em geral, todas as cooperadas abordaram a importância da boa convivência.

A gente trabalha dia sim e dia não, são duas turmas, uma em cada dia. Aí nós tivemos a necessidade porque em todas as empresas tem férias, tem folga, então nós achamos assim, vamos dividir um grupo de pessoas que uns cozinha, uns tem o dom de lavar, uns de passar. Então nós fizemos duas turmas, mas isso dividiu ainda mais o pessoal (C12).

Em relação ao trabalho relataram que as discussões surgem em função das condições em que a cozinha, os alimentos e a organização em geral são deixados de uma turma para a outra no dia seguinte. Entretanto, na maioria das vezes, as discussões relacionam-se à vida pessoal/familiar das cooperadas. As discussões que ocorrem no ambiente de trabalho assemelham-se às discussões que ocorrem no ambiente doméstico e com frequência baseadas em temas familiares.

As cooperadas identificaram como atividades a serem desempenhadas na cooperativa: cozinhar, lavar vasilhas, limpar a área do restaurante e banheiros, atendimento aos clientes. A divisão das atividades de trabalho era um fator gerador de conflitos por considerarem que umas trabalhavam mais que as outras e que não havia disposição de todas para ajudar quem está sobrecarregado. A presidente da cooperativa foi quem decidiu pela divisão das atividades e era responsável pelo controle financeiro.

A questão financeira é um aspecto que permeia as relações no trabalho. Relacionada à gestão financeira, ressaltavam a não prestação de contas. Esse é um fator de instabilidade e gerador de uma série de boatos, fofocas que interferem no relacionamento entre as cooperadas no cotidiano do trabalho e levou à saída de cooperadas.

Nós fazia uma prestação de contas item por item e isso deu um polêmica na comunidade em geral porque algumas pessoas daqui chega em casa e passa de uma forma que poderia dizer assim que fizemos uma balanço, mas diziam que nós tamo devendo doze mil e tanto e não falava o resto e eu não tinha como falar "cala a sua boca". Então, eu falei "quando vocês quiser prestação de contas abre o meu caderno", porque eu não vou falar mais porque isso gerou polemica na ilha toda e parece que nós tamos devendo e não vamo pagar mais ninguém (C12).

Ela [a presidente] é muito boa pessoa, mas tudo ficou na mão dela. Mas aí, o quê que acontece? 
Não presta conta de nada como nós aprendemos que tem que ser prestado, fica tudo na mão dela, não mostra quanto gasta, quanto ganha, não fala o que comprou e o que deixou de comprar e a gente vê que dá dinheiro, tem semana que não dá muito, mas dá (C6).

Segundo as cooperadas, o desfio do siri, quando realizado em quantidade maior propicia um melhor retorno financeiro semanal do que o trabalho na cooperativa, entretanto, as cooperadas que permanecem não têm habilidade para o desfio em grande quantidade. Apesar do reconhecimento da influência dos laços de parentesco na aceitação da gestão financeira da cooperativa, a permanência das cooperadas também estava relacionada à dificuldade de obter um trabalho formal e de se adaptarem às regras do trabalho formal.

A inserção e a permanência das cooperadas na cooperativa eram mediadas pelo relacionamento familiar. Entravam por indicação de algum familiar e também há casos de desligamento em função de brigas e discussões com familiares, seja no ambiente de trabalho ou doméstico. Portanto, era característica uma transposição do relacionamento familiar para o ambiente de trabalho e do relacionamento que se desenvolve no ambiente de trabalho para o contexto familiar. Ainda não eram claras para as cooperadas as diferenças entre relacionamento pessoal/familiar e relacionamento profissional, o que ocasionava uma série de boatos, que, por vezes, transformavam-se em conflitos. Portanto, havia uma permanência de relações anteriores, uma transposição da estrutura familiar para a estrutura organizacional: "Aqui nóis é tudo parente. Todo mundo foi criado junto na ilha ou é casada com homem da ilha, por isso que tem vez que dá confusão em casa e acaba dano briga aqui na cooperativa também" (C3).

\section{Cooperação}

Compreender as relações de cooperação na cooperativa é diferente de analisá-las no contexto da comunidade ou no contexto familiar. Isso porque, historicamente, a atividade de trabalho vivenciada e aprendida pelas cooperadas é baseada em uma estrutura individualizada, enquanto no contexto da comunidade e familiar há forte participação e entrosamento, principalmente nos momentos de crise pessoal ou familiar, quando todos participam e buscam ajudar.

Foi indagado às cooperadas como elas explicariam a alguém o que é uma cooperativa e, em seguida, como explicariam o que é cooperação. Expressaram grande dificuldade nessas questões e retrataram situações contraditórias. Ao explicarem o que é uma cooperativa, algumas diziam, inicialmente, que não sabiam fazê-lo. Em geral, remetiam à ideia de cooperativa como um local de trabalho em que um coopera com o outro, compreende o outro, ajuda o outro, faz parceria, tem união entre as pessoas, conforme relatos: "É uma pessoa ajudar a gente, ter união da gente" (C1); "Hum... é assim ajudar, né?" (C2); "Não sei... é difícil, mas acho que é pessoa ajudando a outra no momento difícil também porque é claro que a gente discute também, mas depois a gente se entende e fica tudo normal uma ajudando a outra" (C3). "É um compreender o outro" (C5); "É a gente entender as necessidades dos outros e, se puder ajudar, ajudar, tá sempre ali cooperando" (C7); "Cooperação é trabalhar em grupo, um ajudando o outro, eu acho assim" (C11); "Ah... eu acho que cooperativa é cooperar, é todo mundo tá junto. O que eu vejo mais é essa parte de união" (C12).

Parte das cooperadas não identificou a cooperação no próprio cotidiano de trabalho, não observando ajuda de uma cooperada à outra no trabalho. Algumas expressaram que trabalhar junto em um mesmo local, com a denominação de cooperativa, não significa que haja cooperação, mas apenas compartilhamento de espaço físico. Ainda retrataram que na comunidade tem-se o costume do trabalho individualizado, portanto, as cooperadas tendem a transpor para a experiência na cooperativa esse modelo, ou seja, cada um produz o que precisa para sobreviver, vende de acordo com a necessidade, não há abertura para pensar em um processo de trabalho que envolva outras pessoas. Enquanto outras retrataram uma melhora 
significativa nas relações interpessoais no trabalho nos últimos anos e consideraram que fatores como a diminuição do número de cooperadas, bem como o fato de terem aprendido a exercer todas as tarefas realizadas no restaurante foram importantes para o desenvolvimento de ações cooperativas.

Eu não entendo o que é cooperação, eu não entendo... eu acho que não tem nada a ver com cooperativa não. É uma ajuda, é um ajudar o outro, mas aqui não tem isso, aqui não tem isso. Eles falam sempre que nós somos cooperadas, não somos, aqui nós não somos cooperadas porque ninguém ajuda ninguém, aqui não tem nada disso de um ajudar o outro, um quer engolir o outro. Pra mim aqui é o espaço e a gente trabalha junto aqui (C10).

Eu não sei se foi a convivência, eu não sei se foi o número de pessoas, eu não sei, mas melhorou. (...) sendo que agora todo mundo sabe fazer quase tudo e foi o que foi melhorando também quando todo mundo foi aprendendo a fazer quase tudo, isso ajudou na cooperação (C11).

Considerando que o trabalho das desfiadeiras de siri era extremamente individualizado, apesar de realizado em ambiente coletivo, as cooperadas que permaneceram na cooperativa reconheceram o desenvolvimento de um ponto de vista diferenciado para o trabalho, voltado também ao outro, identificando o que pode fazer para ajudar. Duas cooperadas que trabalhavam em uma lanchonete da área nobre de Vitória relataram ter alcançado um diferencial a partir da vivência na cooperativa, conforme evidencia o depoimento do proprietário do estabelecimento, que disse ter percebido nelas uma forma de agir diferente, mais cooperativa, que não percebe nos demais funcionários.

Diante da falta de estrutura administrativa, de um relacionamento profissional, a cooperação entre as cooperadas baseia-se mais nos vínculos pessoais/familiares. Há vários relatos do envolvimento das cooperadas, principalmente da presidente, com questões de ordem familiar que estejam dificultando a vida de uma colega. Nesse sentido, a presidente torna-se figura de referência, tendo sido citada por todas como alguém que se preocupa e age para ajudá-las a resolver problemas de toda ordem. $\mathrm{O}$ depoimento a seguir ilustra que parece haver um estilo de cooperação na comunidade que, na visão de algumas cooperadas, estende-se à cooperativa:

...eu passei quase 20 dias sem por nada de comida na boca, quem cuidava de mim era meu filho mais velho que me dava banho e cuidava de mim. Eu saí dessa, eu agradeço a uma pessoa, a presidente da cooperativa, porque ela não é uma presidente ela tem um dom diferente das outras pessoas, sabe o que ela fez, ela foi na minha casa mais o marido dela me tirar da cama. Eu acho que se não tivesse a cooperativa eu não tinha saído (C7).

\section{Discussão}

A partir dos dados obtidos, são destacados alguns aspectos centrais do papel dos relacionamentos interpessoais na construção e na manutenção de uma cooperativa de produção. $\mathrm{O}$ primeiro aspecto refere-se à construção do sistema cooperativo como uma reorganização das relações interpessoais. $O$ segundo trata da dimensão sociocultural e ambiental e da transferência das relações familiares e de amizade para o trabalho. Apesar do modelo de Hinde (1997) apresentar estruturas socioculturais e ambiente físico como duas dimensões distintas, na prática, não parece possível tratar o ambiente como algo isolado de suas determinações sociais e culturais. Finalmente, um terceiro aspecto aborda a liderança e o processo decisório como partes integrantes da dinâmica da cooperativa. 
Do ponto de vista do relacionamento interpessoal, a formação da cooperativa exige nova estrutura e dinâmica nas relações entre as desfiadeiras, afetando ainda a comunidade da ilha. A mudança econômica traz consigo novas formas de produção, que exigem novos papéis e novas relações entre as pessoas, as quais são inseridas em uma estrutura de trabalho que requer o desenvolvimento de relações profissionais; entretanto, os padrões de relacionamento na cooperativa parecem atrelados às relações familiares e na comunidade, com amigos e parceiros.

Ao entrar na esfera profissional, o indivíduo não é desprovido dos demais papéis sociais que representa, principalmente os papéis familiares de mãe, esposa, filha, tia. Os dados permitiram observar uma permeabilidade entre os diversos papéis familiares e profissionais vivenciados pelas cooperadas, sendo, por vezes, a cooperativa uma extensão da casa das cooperadas. Assim não só preocupações, sentimentos de culpa, desgaste emocional, conflitos, mau humor, mas também aspectos positivos, como tranquilidade, disponibilidade para ajudar, alegria, bom humor, originam-se em ambas as esferas e interferem nos relacionamentos estabelecidos no espaço familiar e profissional.

$\mathrm{Na}$ cooperativa, o que é transposto para a esfera profissional são as próprias relações familiares; portanto, falar das relações interpessoais na cooperativa estudada implica em ressaltar que elas são de ordem primordialmente familiar. As fronteiras físicas da família e organização coincidem, pois a cooperativa está localizada onde as cooperadas e seus familiares sempre viveram, o entorno é totalmente familiar. A presença dos laços familiares cria um sistema organizacional familiar baseado na lealdade e na submissão, que impede qualquer movimento contrário. Nem tudo, porém, é desvantagem. A relação cooperativa/família carrega consigo lealdade, dedicação, sensibilidade à vivência dos colegas, sacrifícios feitos pela família, orgulho familiar.

Na cooperativa foram observadas mais variáveis afetivas, como lealdade e dedicação ao familiar mais próximo, do que variáveis racionais que estariam ligadas aos aspectos administrativos. A questão está em como conciliar conflitos, interesses, intenções, funções, consanguinidade, afetividade e hierarquia doméstica com gestão profissional dos negócios. A ideia de profissionalização das relações na cooperativa carrega consigo a constituição de normas profissionais condutoras de eficiência/eficácia, contudo, buscando unir relacionamento familiar e todo seu sentido histórico-simbólico-subjetivo com a objetividade e as exigências administrativas de uma organização para sobreviver no mercado atual.

Trata-se de uma cooperativa formada por mulheres, em sua maioria, excluídas do mercado de trabalho formal, que tiveram na cooperativa a primeira oportunidade de reencaixe econômico, social e identitário (Rodriguez, 2002). A partir da cooperativa, podem ser alcançados a valorização e o reconhecimento da profissão de desfiadeira de siri e as sócias conseguem estabelecer um valor mínimo para o produto que comercializavam.

A liderança de um empreendimento cooperativo é complexa. Geralmente é uma situação ambígua, visto que a autogestão é o foco em uma organização cooperativa. A presidente é a figura central da cooperativa e o poder de decisão encontra-se em suas mãos. Praticamente, não há participação das cooperadas nas decisões relativas à rotina de trabalho e à gestão financeira. Acrescido a isso, a presidente exerce ainda grande influência na vida familiar das demais cooperadas, sendo uma figura de referência do grupo para solucionar problemas de toda ordem.

Considerando a realidade estudada na cooperativa das desfiadeiras, quanto à liderança, foram observadas e abordadas pelas entrevistadas dificuldades em relação à gestão democrática. As relações interpessoais liderança/cooperadas parecem preservadas quando não se trata de aspectos de trabalho, pois, diante de alguma situação de conflito ou de desestruturação familiar, recorrem à presidente. 
As dificuldades para o desenvolvimento de uma cultura autogestionária estavam presentes nas expectativas das cooperadas no momento de formação da cooperativa, quando havia a valorização do assalariamento, da carteira assinada, a incompreensão quanto à necessidade de horários de trabalho, a falta de entendimento das características e das peculiaridades de uma cooperativa, a participação na cooperativa vista como falta de opção de emprego e a permanência na cooperativa vista como temporária. Parte fundamental do processo de formação de uma cooperativa encontra-se na preparação dos trabalhadores para o exercício da atividade nesse novo contexto, mas há uma barreira comum nas cooperativas populares: o baixo nível de escolaridade (Albuquerque, 1994; Lima, 2004). Entretanto, a baixa escolaridade deve ser vislumbrada como possível limitação a ser transposta por meio de cursos de qualificação dos cooperados.

Ao propor a criação de uma organização cooperativa, é importante que seja feita uma análise da atividade que os futuros membros da cooperativa em questão realizavam antes de entrar para a cooperativa, compreender como era a organização do trabalho naquele contexto e avaliar quantos cooperados seriam necessários para que o desenvolvimento das novas atividades seja compatível com um rendimento financeiro mínimo para a manutenção da cooperativa e de seus membros. Na Ilha das Caieiras, tradicionalmente, a quantidade de investimento no trabalho estava relacionado ao necessário para a sobrevivência diária. A organização do trabalho era baseada no indivíduo, apesar de ser uma atividade realizada por quase todas as mulheres locais e em ambiente coletivo.

Assim, após o estudo de como é a organização do trabalho na comunidade onde deverá ser implementada a cooperativa, é importante compreender os fatores facilitadores e dificultadores para a criação de uma organização do trabalho que seja coerente com a atividade desenvolvida e com as exigências de uma organização cooperativista. Após esse processo, cabe realizar a construção coletiva dos objetivos da cooperativa e do processo de trabalho a ser implementado. É importante construir regras, rotinas, procedimentos, superando as diferenças em prol de um projeto comum atendendo, inclusive, às exigências de um mercado competitivo.

A percepção que as cooperadas expressaram do que é uma cooperativa e a cooperação estava baseada na vivência cotidiana. As cooperadas estavam voltadas para a batalha pela sobrevivência individual diária e a permanência na cooperativa tem sido fortemente baseada na falta de outras oportunidades que avaliem como melhores.

Portanto, ainda há muito a ser feito para o avanço de ações de cooperação na cooperativa estudada. Sem dúvida, a própria experiência de trabalho coletivo é uma evolução que as mulheres da ilha, com toda dificuldade e empecilhos quanto à própria capacitação para gestão de um negócio, estão conseguindo vencer. A história da comunidade tem episódios de avanços na cooperação, alternando-se com a busca individual. Possivelmente, o estilo de cooperação na comunidade não está adequado ao tipo de cooperação na cooperativa.

Com relação às redes interorganizacionais visando a cooperação entre cooperativas, com base nas relações interpessoais, a cooperativa investigada apresentava-se completamente isolada. Não havia qualquer relação com outras cooperativas. Também não foi percebida qualquer mobilização no sentido de estabelecer contatos para desenvolvimento de parcerias com agências de turismo ou qualquer outra organização (Batschauer \& Campos, 2005; Gonçalves, 2005; Silva, 2004).

Cursos de formação e aprimoramento são fundamentais para instrumentalizar as cooperadas para a realização de atividades com qualidade e para convivência em uma organização cooperativa. É fácil perceber a dificuldade para assimilar novas formas de pensar e de agir, colocando-as em prática de modo a sempre levar em consideração o outro, por mais elevadas que sejam as metas de democracia, igualdade e autogestão. 


\section{Considerações finais}

Particularmente, quanto à cooperativa investigada, algumas considerações podem ser feitas: a necessidade de estudos prévios das condições sociais e históricas para a implantação de uma cooperativa, incluindo um estudo das redes de relações interpessoais e como estas serão afetadas pelo novo empreendimento; a necessidade da formação das pessoas que irão participar do empreendimento, levando-se em conta a história da população alvo e a história da atividade a ser desenvolvida no empreendimento, buscando sua formação técnica, mas também social e administrativa; a necessidade de acompanhamento do desenvolvimento organizacional e interpessoal, incluindo as relações profissionais.

A presente pesquisa apresentou uma perspectiva dos relacionamentos como uma contribuição específica para os estudos organizacionais, particularmente no caso das cooperativas. Essa perspectiva permite compreender a estrutura e a dinâmica das cooperativas a partir dos relacionamentos interpessoais em sua história e funcionamento atual. $\mathrm{O}$ foco nos relacionamentos contribui para a compreensão de uma estrutura complexa, complementando outras perspectivas de investigação. Permite também subsidiar formas de capacitação dos associados no âmbito das relações interpessoais, visando desenvolver as relações profissionais com o público interno e externo à cooperativa, incluindo fornecedores e clientes, entre outros.

Finalmente, uma dificuldade que emerge das propostas de Hinde é a extensão e a complexidade que tal perspectiva gera. Isso não impede que, futuramente, sejam investigadas em maior profundidade cada dimensão específica dos relacionamentos em organizações cooperativas.

\section{Referências}

Adebayo, D. O. \& Udebge, J. B. (2004). Gender in the boss-subordinate relationship: a Nigerian study. Journal of Organizational Behavior, 25 (4), 515-525.

Albuquerque, F. J. B. (1994). Estudio del cooperativismo agrario desde la perspectiva de la psicología social. Tese de Doutorado, Departamento de Psicologia, Universidade Complutense de Madri, Madri.

Albuquerque, F. J. B. \& Macareño, R. P. (1999). Considerações não ortodoxas sobre as cooperativas e o cooperativismo. Psicologia $\mathcal{G}$ Sociedade, 11 (2), 23-41.

Allinson, C. W., Armstrong, S. J. \& Hayes, J. (2001). The effects of cognitive style on leader-member exchange: a study of manager-subordinate dyads. Journal of Occupational and Organizational Psychology, 74 (2), 201-220.

Bardin, L. (1977). Análise de conteúdo. Lisboa: Edições 70.

Barfknecht, K. S., Merlo, A. R. C. \& Nardi, H. C. (2006). Saúde mental e economia solidária: análise das relações de trabalho em uma cooperativa de confecção de Porto Alegre. Psicologia $\mathcal{E}$ Sociedade, 18 (2), 54-61.

Batschauer, J. \& Campos, R. R. (2005). Cooperação em sistemas produtivos e inovativos locais: o papel das organizações e reflexos sobre o capital social. VIII Encontro de Economia da Região Sul, Porto Alegre.

Becker, J., Ayman, R. \& Korabik, K. (2002). Discrepancies in self/subordiantes' perceptions of leadership behavior: leader's gender, organizational context, and leader's self-monitoring. Group and Organization Management, 27, 226-244.

Bogdan, R. C. \& Biklen, S. K. (1994). Investigação qualitativa em educação. Porto: Porto Editora.

Buskens, V. \& Snijders, C. (1997). Individual heuristics and the dynamics of cooperation in large groups. Psychological Review, 104 (4), 792-800.

Clemente, M., Albuquerque, F. J. B. \& Reyes, T. (1993). Análisis del conflicto en el interior de las cooperativas agrarias y estrategias de superación. Madri: Fundación Largo Caballero. 
Chen, Z. (2001). Further investigation of the outcomes of loyalty to supervisor: job satisfaction and intention to stay. Journal of Managerial Psychology, 16 (8), 650-660.

Coglieser, C. C. \& Schriesheim, C. A. (2000). Exploring work unit context and leader-member exchange: a multilevel perspective. Journal of Organizational Behavior, 21 (5), 487-511.

Cooper-Thomas, H. \& Anderson, N. (2002). Newcomer adjustment: the relationship between organizational socialization tactics, information acquisition, and attitudes. Journal of Occupational and Organizational Psychology, 75 (4), 423-437.

Correia, A. D. C. \& Moura, K. R. L. (2001). A apreensão da cultura e o não-compartilhamento dos valores cooperativistas em uma cooperativa sediada em Natal/RN. Caderno de Pesquisas em Administração, 8 (4), $27-40$.

Coutinho, M. C., Beiras, A., Picinin, D. \& Lückmann, G. L. (2005). Novos caminhos, cooperação e solidariedade: a psicologia em empreendimentos solidários. Psicologia ES Sociedade, 17 (1), 17-28.

Danheiser, P. R. \& Graziano, W. G. (1982). Self-monitoring and cooperation as a self-presentational strategy. Journal of Personality and Social Psychology, 42 (3), 497-505.

Duffy, M. K. \& Ferrier, W. J. (2003). Birds of a feather? How supervisor-subordinate dissimilarity moderates the influence of supervisors behaviors on workplace attitudes. Group and Organization Management, 28 (2), $217-248$.

Finkelstein, L. M., Allen, T. D. \& Rhoton, L. A. (2003). An examination of the role of age in mentoring relationships. Group and Organization Management, 28, 249-281.

Frantz, W. (2001). Educação e cooperação: práticas que se relacionam. Sociologias, 6, 242-264.

Furnham, A. (2002). Rating a boss, a colleague and a subordinate. Journal of Managerial Psychology, 17 (8), 655-671.

Garcia, A. (2005). Relacionamento interpessoal: uma área de investigação. In Relacionamento interpessoal: olhares diversos (pp. 7-28). Vitória: GM Gráfica e Editora.

Garcia, S. M. (2002). Power and the illusion for transparency in negotiation. Journal of Business and Psychology, 17 (1), 133-144.

Gonçalves, C. M. (2005). O papel das relações interpessoais em redes interorganizacionais. Dissertação de Mestrado, Programa de Pós-Graduação em Engenharia de Produção, Universidade Federal de Santa Catarina, Florianópolis.

Hinde, R. A. (1997). The dialetical personal relationships. Cambridge: Cambridge University.

Hinde, R. A. \& Groebel, J. (1991). Cooperation and prosocial behaviour. Cambridge: Cambridge University.

Hinde, R. A., Finkenauer, C. \& Auhagen, A. E. (2001). Relationships and the self-concept. Personal Relationships, 8 (2), $187-204$

Jehn, K. A. \& Shah, P. P. (1997). Interpersonal relationships and task performance: an examination of mediating processes in friendship and acquaintance groups. Journal of Personality and Social Psychology, 72 (4), 775 790.

Lefkowitz, J. (2000). The role of interpersonal affective regard in supervisory performance ratings: a literature review and proposed causal model. Journal of Occupational and Organizational Psychology, 73 (1), 67-85.

Leonard, J. S., Levine, D. I. \& Joshi, A. (2004). Do birds of a feather shop together:? The effects on performance of employees similarity with one another and with customers. Journal of Organizational Behavior, 25 (6), 731 754.

Lievens, F. \&. Paepe, A. D. (2004). An empirical investigation of interviewer-related factors that discourage the use of high structured interviews. Journal of Organizational Behavior, 25 (1), 29-46.

Lima, M. E. A. (1996). Os equívocos da excelência. Petrópolis: Vozes.

Lima, J. C. (2004). O trabalho autogestionário em cooperativas de produção: o paradigma revisitado. Revista Brasileira de Ciências Sociais, 19 (56), 45-62.

Maciel, R. H., Sena, F. C. \& Sabóia, I. B. (2006). O mal-estar nas novas formas de trabalho: um estudo sobre a percepção do papel dos cooperados em uma cooperativa de trabalho autogestionário. Revista Mal-Estar e Subjetividade, 6 (2), 535-560.

Mangam, L. L. (1981). Relationships at work: a matter of tension and tolerance. In S. Duck \& R. Gilmour (Eds.), Personal relationships 1: studying personal relationships (pp. 197-214). London: Academic Press. 
Messick, D. M. \& Liebrand, W. B. G. (1995). Individual heuristics and the dynamics of cooperation in large groups. Psychological Review, 102, 131-145.

Morand, D. A. (2000). Language and power: an empirical analysis of linguistic strategies used in superiorsubordinate communication. Journal of Organizational Behavior, 21 (3), 235-248.

Nascimento, A. B. P. S. (2005). Uma análise, das cooperativas no Brasil. II ENEDS, Rio de Janeiro.

Nasciutti, J. C. R., Dutra, F. S., Matta, J. S. \& Lima, T. R. (2003). Cooperação e autonomia: desafios das cooperativas populares. Cadernos de Psicologia Social e do Trabalho, 6, 91-107.

Pelled, L. H., Xin, K. R. \& Weiss, A. M. (2001). No es como mí: relational demography and conflict in a Mexican production facility. Journal of Occupational and Organizational Psychology, 74 (1), 63-84.

Perry, E. L., Kulik, C. T. \& Zhou, J. (1999). A closer look at the effects of subordinate-supervisor age differences. Journal of Organizational Behavior, 20 (3), 341-357.

Rocha, F. E. C., Zoby, J. L. F., Gastal, M. L. \& Xavier, J. H. V. (2003). Mapeamento das relações interpessoais em três assentamentos de reforma agrária de Unaí, MG. Cadernos de Ciência Ë Tecnologia, 20 (2), 305-323.

Rodríguez, C. (2002). À procura de alternativas econômicas em tempos de globalização: o caso das cooperativas de recicladores de lixo na Colômbia. In B. S. Santos (Org.), Produzir para viver. Rio de Janeiro: Civilização Brasileira.

Santos, B. S. (2002). Produzir para viver. Rio de Janeiro: Civilização Brasileira.

Scopinho, R. A. \& Martins, A. F. G. (2003). Desenvolvimento organizacional e interpessoal em cooperativas de produção agropecuária: reflexão sobre o método. Psicologia E Sociedade, 15 (2), 124-143.

Silva, C. J. (2004). O cooperativismo como alternativa estratégica. In C. Bitencourt (Org.), Gestão contemporânea de pessoas: novas práticas, conceitos tradicionais. Porto Alegre: Bookman.

Silvester, J., Anderson-Gough, F. M., Anderson, N. R. \& Mohamed, A. R. (2002). Locus of control, attribution and impression management in the selection interview. Journal of Occupational and Organizational Psychology, 75 (1), 59-76.

Singer, P. \& Souza, A. R. (2000). A economia solidária no Brasil: a autogestão como resposta ao desemprego. São Paulo: Contexto.

Singer, P. (2001). A economia solidária. Revista Teoria e Debate, 1 (47), 54-60.

Singer, P. (2002). Introdução à economia solidária. São Paulo: Perseu Abramo.

Smith, M. A. \& Canger, J. M. (2004). Effects of supervisor 'big five' personality on subordinate attitudes. Journal of Business and Psychology, 18 (4), 465-481.

Smith, W. J., Hamington, K. V. \& Neck, C. (2000). Resolving conflict with humor in a diversity context. Journal of Managerial Psychology, 15 (6), 606-625.

Strauss, J. P., Barrick, M. R. \& Connerley, M. L. (2001). An investigation of personality similarity effects (relational and perceived) on peer and supervisor ratings and the role of familiarity and liking. Journal of Occupational and Organizational Psychology, 74 (5), 637-657.

Tett, R. P. \& Murphy, P. J. (2002). Personality and situation in co-worker preference: similarity and complementarity in worker compatibility. Journal of Business and Psychology, 17 (2), 223-243.

Thorsteinson, T. J. \& Balzer, W. K. (1999). Effects of coworker information on perceptions and ratings of performance. Journal of Organizational Behavior, 20 (7), 1157-1173.

Yang, J. \& Mossholder, K. W. (2004). Decoupling task and relationship conflict: the role of intragroup emotional processing. Journal of Organizational Behavior, 25 (5), 589-605.

\section{Endereço para correspondência}

raquel.miranda@ufv.br, agnaldo.garcia@pq.cnpq.br

Recebido em: 24/09/2009

Revisado em: 07/03/2010

Aprovado em: 17/03/2010 